\title{
Livro Didático e Educação Ambiental em atenção à Saúde
}

\author{
Libro Didáctico y Educación Ambiental en atención a la Salud \\ The Didactic Book and Environmental Education in Health care
}

\author{
Rosangela Inês Matos Uhmann ${ }^{1}$ \\ Fernanda Seidel Vorpagel ${ }^{2}$ \\ Rafaela Rossana Scheid ${ }^{3}$
}

\begin{abstract}
Resumo
O Livro Didático (LD) é hoje um dos recursos mais utilizados pelos sujeitos escolares em sala de aula. O que nos levou ao objetivo de analisar um LD do $1^{\circ}, 2^{\circ}$ e $3^{\circ}$ ano de Química do Ensino Médio destacando excertos relacionados à Educação Ambiental (EA) com atenção para a saúde a alimentação. Para tanto, organizamos os excertos e as sessões em um quadro para compreender a questão da EA, saúde e alimentação, dentre outras implicações ao ensino de Química. Portanto, em observação aos LD destacamos nas sessões, as temáticas: ar, água, energia, petróleo, consumismo (reciclagem), dentre outros, pois em nosso entendimento é preciso elencar a questão da EA, intrínseco à saúde, no LD. Enfim, urge dizer que a EA é um tema fundamental para a preservação do ambiente, o que acarreta estar cuidando da saúde junto aos estudos escolares.
\end{abstract}

Palavras-Chave: Livro Didático de Química; Educação Ambiental; Qualidade de Vida.

\section{Resumen}

El Libro Didáctico (LD) es hoy uno de los recursos más utilizados por los sujetos escolares en el aula. Lo que nos llevó al objetivo de analizar un LD del $1^{\circ}, 2^{\circ}$ y $3^{\circ}$ año de Química de la Enseñanza Media destacando extractos relacionados a la Educación Ambiental (EA) con atención para la salud a la alimentación. Para ello, organizamos los extractos y las secciones en un cuadro para comprender la cuestión de la EA, salud y alimentación, entre otras implicaciones a la enseñanza de Química. Por lo tanto, en observación a los LD destacamos en las secciones, las temáticas: aire, agua, energía, petróleo, consumismo (reciclaje), entre otros, pues en nuestro entendimiento es posible enumerar la cuestión de la salud intrínseca al LD. En fin, urge decir que la EA es un tema fundamental para la preservación del ambiente, lo que acarrea que la salud necesita ser cuidada en los estudios escolares.

Palabras claves: Libro Didáctico de Química; Educación Ambiental; Calidad de Vida.

\begin{abstract}
The Didactic Book (DB) is now one of the resources most used by school people in the classroom. This took us to the objective of analyzing a DB of the 1st, 2nd and 3rd year of High School Chemistry highlighting excerpts related to Environmental Education (EE) with attention to health and alimentation. For that, we organize the excerpts and the sections in a board as beginning to understand the issue of EE, health and nutrition, between other implications to the teaching of Chemistry. However, observing the DB, we highlight in the sections, the topics: air, water, energy, petroleum, consumerism (recycling), in the middle of others, because in our understanding it is necessary to elnec the issue of EE, intrinsic to health, in DB. Finally, it is important to say that $\mathrm{EE}$ is a fundamental theme for environmental preservation, which implies that health need to be taken care of in school studies.

\footnotetext{
${ }^{1}$ Doutora em Educação nas Ciências; Universidade Regional do Noroeste do Estado do Rio Grande do Sul UNIJUI; Ijui, Rio Grande do Sul, Brasil; rosangela.uhmann@uffs.edu.br

${ }^{2}$ Graduação em Química Licenciatura, Universidade Federal da Fronteira Sul-UFFS; CerroLargo, Rio Grande do Sul, Brasil; vorpagelfernanda@gmail.com

${ }^{3}$ Graduação em Química Licenciatura Universidade Federal da Fronteira Sul-UFFS; CerroLargo, Rio Grande do Sul, Brasil; rafasrossana@gmail.com
} 
Keywords: Didactic Book of Chemistry; Environmental Education; Life quality.

\section{Introdução}

Entende-se que: “[...] o papel central da educação para a construção de um mundo socialmente justo e ecologicamente equilibrado requer responsabilidade individual e coletiva em níveis local, nacional e planetário" (BRASIL, 1997, p. 22). Neste sentido, a Educação Ambiental (EA) constitui ponto de partida para o enfrentamento das questões socioambientais. Diante da perspectiva socioambiental e do atual contexto dos recursos naturais surge a necessidade de reflexão pelo ser humano sobre as práticas cotidianas.

A EA precisa estar presente em todos os níveis educacionais, desde as primeiras fases escolares, pois é neste contexto que emergem os primeiros diálogos reflexivos entre professor e aluno. Estes diálogos buscam intervir no debate e nas práticas relativas à construção de alternativas metodológicas de trabalho com a EA em contexto escolar, fazendo uso de diferentes materiais didáticos, visto que um dos exemplos é o Livro Didático (LD). Desta forma, todos os alunos têm a oportunidade de serem sensibilizados pela temática da EA extrapolando os muros escolares, invadindo com atitudes conscientes de cuidado ambiental suas casas, de fundamental importância para elencar a EA.

Como muitos professores usam o LD como base para suas aulas é valorizável que se observe como este material didático está organizado, aqui em especial nosso olhar se volta ao conhecimento da preservação ambiental, bem como a relação com a saúde, em observação ao conteúdo focada na relação com a EA. Assim, os alunos tendem a desenvolver projetos ambientais para aprimorar o pensamento crítico, Güllich contribui:

[...] o livro tem sido determinante da prática do professor em sala de aula e do ponto de vista das práticas, os experimentos propostos pelos livros são geralmente empregados em aula, contribuindo de modo direto a determinação do tipo de aula a ser ministrada/produzida (2013, p.3).

O LD é um “[...] instrumento construtor de uma cultura nacional, é assaz importante que ele acompanhe as mudanças dos saberes-pilar dos novos paradigmas da pósmodernidade" (SANTOS, 2088, p. 54). Nesse sentido, realizamos um estudo sobre as questões socioambientais no LD de Química do $1^{\circ}, 2^{\circ}$ e $3^{\circ}$ ano do Ensino Médio. Cabe destacar, que a problematização se deteve a observar a articulação das questões relacionadas à saúde e alimentação.

Entendendo que a EA engloba aspectos, como os conceitos da relação da espécie humana com a natureza, que precisamos que a temática seja de discussão, especialmente no 
ensino formal para contribuir na formação de sujeitos capazes de compreender o mundo e agir nele de forma crítica. Visto que,

[...] a EA promove a conscientização e esta se dá na relação entre o "eu" e o "outro", pela prática social reflexiva e fundamentada teoricamente. A ação conscientizadora é mútua, envolve capacidade crítica, diálogo, a assimilação de diferentes saberes, e transformação ativa da realidade e das condições de vida (LOUREIRO, 2006, p. 29).

Assim, para explorarmos as questões socioambientais em uma ferramenta didática ampla, a exemplo do LD, apresentamos abaixo o caminho metodológico adotado para o tecimento deste estudo. Na sequência, é problematizado a EA nos LDs de Química e no próximo item discutimos a EA em relação à saúde e alimentação, ainda observando quais os aspectos que poderiam avançar no sentido de contemplar mais a EA. Por fim, inferimos a conclusão acerca do presente trabalho.

\section{Metodologias}

O caminho metodológico desta pesquisa foi caracterizado como qualitativa, na qual nos atentamos a identificar a presença de excertos a respeito da EA, com atenção para a saúde e a alimentação. Os LD foram analisados da seguinte forma: os excertos de EA foram destacados de modo que o número das páginas foi contabilizado, independentemente da quantidade de excertos encontrados na mesma página (Quadro 1).

A análise do conteúdo consistiu em identificar os excertos de EA nos LD de Química do $1^{\circ}, 2^{\circ}$ e $3^{\circ}$ ano do Ensino Médio da autora Martha Reis (coleção Química), os quais se encontram no Programa Nacional do Livro Didático - PNLD 2018, disponível na página do Ministério da Educação (MEC).

Após a primeira etapa de catalogação dos excertos de EA localizados, optamos em observar em que parte do LD de Química estavam os excertos de EA, e destes quais estavam intrínsecos à saúde (destas as páginas estão sublinhadas), a exemplo: nos textos de abertura da unidade, foi notícia, entre outras sessões nos três (3) LD de Química explicitado no Quadro 1.

Quadro 1: Número das páginas dos excertos nos Livros Didáticos e as respectivas sessões.

\begin{tabular}{|c|c|c|c|c|}
\hline & LD1 & LD2 & LD3 & Total \\
\hline $\begin{array}{l}\text { Livro } \\
\text { Código } \\
\text { Coleção }\end{array}$ & $\begin{array}{l}\mathrm{LD} 1 / 1^{\circ} \text { ano } \\
\text { 0020P18123101IL } \\
\text { Química }\end{array}$ & $\begin{array}{l}\mathrm{LD} 2 / 2^{\circ} \text { ano } \\
\text { 0020P18123102IL } \\
\text { Química }\end{array}$ & $\begin{array}{l}\text { LD3/3aano } \\
\text { 0020P18123103IL } \\
\text { Química }\end{array}$ & \\
\hline Páginas dos excertos & $\begin{array}{l}8,9, \underline{11}, 23,41,47,56,57 \\
58,59, \underline{60}, 61,67,71,72, \\
\frac{73}{24}, 100,132,196,239,240, \\
\text { e } 285 .\end{array}$ & $\begin{array}{l}\frac{31}{92}, \underline{42}, 45,101, \underline{63}, \underline{64}, \underline{74}, 123, \\
140,163,173,175,198, \\
201,233,235,236,237, \\
259,260,262 \text { e } \underline{285} .\end{array}$ & $\begin{array}{l}8,9,35,42,43,75,147, \\
148,149,154,200,203, \\
210,211,219,220,221, \\
\frac{226}{285}, 260,261, \underline{272}, 281 \mathrm{e}\end{array}$ & \\
\hline Abertura da unidade & 5 & 2 & 4 & 11 \\
\hline
\end{tabular}


RELACult - Revista Latino-Americana de Estudos em Cultura e Sociedade

\begin{tabular}{|l|c|c|c|c|}
\hline Foi notícia & 5 & 11 & 5 & 21 \\
\hline Retomando a notícia & 4 & 6 & 1 & 17 \\
\hline Saúde e sociedade & - & 2 & 3 & 3 \\
\hline $\begin{array}{l}\text { Compreendendo o } \\
\text { mundo }\end{array}$ & 3 & 5 & 2 & 11 \\
\hline Inserido no conteúdo & 7 & 1 & 22 & 10 \\
\hline Total de excertos & 24 & 27 & 27 \\
\hline
\end{tabular}

Fonte: Os autores

O quadro 1 nos impulsionou a fazermos uso de uma metodologia adequada para analisar cada LD de Química, na elaboração de explicações ao investigar por meio dos dados analisados conforme temática desta pesquisa. Com base em Bardin (1995) as etapas de uma “análise de conteúdo” pressupõem: 1- Primeira etapa: Pré-análise (exploração do material, das características... definição do corpus de análise); 2- Segunda etapa: Inferência (destaca causas e consequências... é a análise das categorias pré-estabelecidas, descrição das características) e, 3- Terceira etapa: Interpretação (significado das descrições e informações que ajudam a responder os questionamentos iniciais. Relação entre os dados obtidos e a fundamentação teórica. Apresenta os dados sobre o tema analisado).

O que nos ajudou a tecermos uma análise com foco na construção dos blocos interpretativos, em que recortes dos excertos de cada LD serão usados, sendo possível pontuar os itens a seguir como início da teorização. De modo a compreender a questão da EA, saúde e alimentação, bem como a relação do conteúdo, dentre outras implicações ao ensino de Química.

\section{O Escopo do Livro Didático de Química e a Temática Ambiental}

Os trabalhos serão publicados exatamente como você os submeter. Desta forma, a organização e o esmero são de extrema importância. Por favor, faça uma revisão cuidadosa dos erros gramaticais e de digitação antes da submissão. Os artigos e documentos terão a dimensão mínima de 08 laudas e a máxima de 25 laudas, incluídas bibliografia e notas. Os trabalhos poderão ser redigidos em português, inglês ou espanhol.

O LD tem um papel marcante na educação brasileira, podemos dizer que ele é um dos pilares que sustenta a educação com um dos apoios e/ou guia para os professores que fazem uso do mesmo. Portanto, ele deveria ser mais explorado pelos professores quanto aos conteúdos apresentados, os quais poderiam ser abordados de uma forma mais contextualizada e abrangente no quesito da EA, pois a EA é de fundamental importância para a formação de sujeitos sustentáveis e socioambientalmente conscientes. 
Neves destaca: "Os LDs em geral ainda não tratam de forma satisfatória das questões que envolvem a educação ambiental” (2014, p. 91). Para tanto, a prática da EA no Brasil exige uma relação mais profunda com o conteúdo para que o processo de ambientalização dos sujeitos na área da EA aconteça em todos os níveis escolares.

É importante que os alunos construam seus saberes escolares, por vezes em observação ao LD, assim vão ressignificando os conceitos prévios, no entanto, nossa atenção é relacionar a questão da EA o quanto antes na vida escolar, trazendo desenvolvimento e ampliação dos conhecimentos acerca da temática. Neste sentido: “[...] pode-se dizer que legislações e materiais didáticos relacionados a EA não faltam, mas é preciso ir além, ao resgatar a realidade dos sujeitos escolares e a criticidade dos materiais a serem usados pelos mesmos" (UHMANN, 2013, p. 38).

Compreendemos com Soffiati: “A educação, em seu sentido mais amplo, enfrenta acentuados problemas de qualidade e não alcançou patamares desejáveis de democratização" (SOFFIATI, 2002, p. 23), em que ainda tem a questão e o estudo da EA em meio aos recursos pedagógicos, a exemplo, do LD amplamente utilizado. De acordo com Tristão (2004), essa dimensão da qual tratamos, gera contradição entre desenvolvimento e qualidade de vida, compatíveis com nutrição, saúde e bem-estar da população.

Deste modo, analisar o LD é extrapolar nas interpretações, fazendo apontamentos, inferências, bem como ir construindo algumas ideias a partir das percepções advindas da análise, principalmente de um material como o LD que se destaca como transformador da consciência e das atitudes em sala de aula, pois é amplamente usado em nossas escolas. Para tanto, tal olhar tem mais potencial quando tratar de uma temática, por exemplo, aqui em especial a EA. Educar na era planetária consiste em mudar/transformar nossas ações individuais e coletivas de preservação da vida, saúde, ambiente e recursos naturais considerados finitos, enquanto ainda é possível.

A proposta de observação das sessões (Quadro 2) nos auxiliou para problematizar o estudo sobre a EA no LD. Os excertos de EA encontrados nos 3 LD, na sua maioria não se correlacionam com o conteúdo abordado, são textos isolados que trazem algo sobre a natureza, meio ambiente, reciclagem e desastres ambientais.

Quadro 2: Sessões dos três (3) Livros Didáticos de Química.

\begin{tabular}{|c|l|l|l|}
\hline Seção & \multicolumn{1}{|c|}{ LD1 } & \multicolumn{1}{|c|}{ LD2 } & \multicolumn{1}{|c|}{ LD3 } \\
\hline $\begin{array}{c}\text { Abertura da } \\
\text { unidade }\end{array}$ & $\begin{array}{l}\text { Mudanças climáticas; } \\
\text { Oxigênio e ozônio; Poluição } \\
\text { eletromagnética; Chuva ácida. }\end{array}$ & $\begin{array}{l}\text { Meteorologia e as variáveis do } \\
\text { clima; Poluição da água; Poluição } \\
\text { térmica; Corais; Lixo eletrônico. }\end{array}$ & $\begin{array}{l}\text { Poluição petróleo; } \\
\text { Consumismo; Aditivos } \\
\text { químicos; Atividade nuclear. }\end{array}$ \\
\hline
\end{tabular}


RELACult - Revista Latino-Americana de Estudos em Cultura e Sociedade

\begin{tabular}{|c|l|l|l|}
\hline Foi notícia & $\begin{array}{l}\text { Aquecimento global; Efeito } \\
\text { estufa; Poluição atmosférica. }\end{array}$ & $\begin{array}{l}\text { Impactos ambientais das } \\
\text { queimadas; Poluição da Baía de } \\
\text { Guanabara; Poluição térmica; }\end{array}$ & $\begin{array}{l}\text { Poluição rio; Vazamento } \\
\text { petróleo; Consumismo; } \\
\text { Aditivo químico; Usinas } \\
\text { nucleares. }\end{array}$ \\
\hline $\begin{array}{c}\text { Retomando a } \\
\text { notícia }\end{array}$ & $\begin{array}{l}\text { Chuva artificial; Efeito estufa; } \\
\text { Camada de ozônio; Corrosão. }\end{array}$ & $\begin{array}{l}\text { Umidade do ar; Esgoto e água; } \\
\text { Poluição atmosférica; Reciclagem } \\
\text { do lixo eletrônico. }\end{array}$ & $\begin{array}{l}\text { Vazamento petróleo; Química } \\
\text { verde; Embalagem; Aditivos; } \\
\text { Acidente nuclear. }\end{array}$ \\
\hline $\begin{array}{c}\text { Saúde e sociedade } \\
\text { Compreendendo o } \\
\text { mundo }\end{array}$ & $\begin{array}{l}\text { Poluição; Mudanças } \\
\text { climáticas. }\end{array}$ & - & $\begin{array}{l}\text { Poluição da água; Poluição } \\
\text { térmica; Lixo eletrônico. }\end{array}$ \\
\hline $\begin{array}{c}\text { Inserido no } \\
\text { conteúdo }\end{array}$ & $\begin{array}{l}\text { Energia limpa; Poluição da } \\
\text { água; Saúde; Reciclagem }\end{array}$ & Descarte de pilhas e baterias. & $\begin{array}{l}\text { Consumismo; 5 Erres; } \\
\text { Radioatividade. }\end{array}$ \\
\hline
\end{tabular}

Fonte: Os autores

Mesmo em atenção ao exposto do quadro 2, inicialmente destacamos a seguinte afirmação na abertura do LD1 ano:

[...] o estudo da Química, em particular, vai lhe fornecer informações que farão você compreender melhor o funcionamento do seu corpo e do mundo em que vive. Essas informações ajudarão você a exercer efetivamente a cidadania e a ter consciência de suas escolhas - incluindo o uso da tecnologia -, pois será capaz de avaliar o impacto dessas escolhas tanto no meio ambiente quando na sua saúde (FONSECA, 2016, p. $3)$.

Diante disso, a autora coloca sobre a importância da relação da EA e saúde, no entanto, no decorrer do LD pouco contextualiza esta relação, pois aborda principalmente mudanças climáticas e suas implicações no meio ambiente, ou seja, as questões relacionadas a alimentação e saúde quase não aparecem correlacionada com a EA.

A diversidade dos temas abordados não varia muito, sendo que a maior parte dos excertos encontrados não está inserido ao conteúdo, mas sim em quadros separados. Junto ao conteúdo do LD há pequenas frases que falam sobre a EA, porém o tema reciclagem se destaca em meio aos outros (com 5 páginas). Já nas outras sessões são tratados em sua maioria, a degradação do meio ambiente causada pelas mudanças climáticas.

A degradação do meio ambiente está diretamente ligada à exploração socioambiental, por conseguinte a EA precisa deixar de ser um tema pouco explorado para se tornar o foco na formação da população de modo geral, visto que: “[...] não podemos afirmar que o LD por si só constitui um instrumento que proporciona criticidade do aluno e do professor acerca da temática" (NEVES, 2014, p. 91). O que nos acarreta mais responsabilidade na observação do que diz no LD, pensando ainda para além deste instrumento no que se refere à inserção da EA. 
A partir do exposto no quadro 2 em relação ao LD2 foi possível evidenciarmos temáticas ambientais, a exemplo, da poluição da água. A questão se encontra articulada aos Jogos olímpicos, uma vez que, os atletas: “[...] terão que nadar e velejar em águas contaminadas por fezes humanas que se arriscam a contrair alguma doença e não poder concluir as provas" (FONSECA, 2016, p. 63). Deste modo, a EA é remetida à saúde, uma vez que, menciona o risco de doenças estomacais, respiratórias, entre outras.

Isto posto, vemos que a poluição da água também afeta a alimentação, como por exemplo na lavagem de hortaliças e verduras. Assim, cabe ao professor contextualizar de forma mais ampla em escala local/global, as implicações da poluição da água. Entendendo que o LD2 apresenta uma perspectiva, a qual, precisa ser ampliada no sentido de evidenciar a questão com outros aspectos relevantes para um ambiente saudável e sustentável. Em relação a isso, o LD2 também apresenta a questão da poluição térmica e lixo eletrônico. Diante do exposto, Uhmann e Zanon apontam:

Construir significados referentes ao conteúdo escolar, na interação social frente aos problemas socioambientais, mobiliza e propicia condições para que todos possam pensar e aprender sobre as transformações naturais e impostas pelo ser humano, no uso correto de pilhas e baterias, redução do consumo de energia elétrica, entre outros, por exemplo, sendo que só ensina aquele que também aprende nas ações pedagógicas, mediação e dialogicidade, uns com os outros (2012, p. 13).

A partir do exposto no quadro 2 em relação ao LD3 é possível perceber a questão da poluição do petróleo no trabalho com os hidrocarbonetos, assim como a atividade nuclear que necessita de cuidado e conhecimento sobre o assunto. Outra questão é o aditivo químico, embalagem e o consumismo, além da reciclagem bem preliminar. Assim destacamos para a necessidade de se trabalhar principalmente a redução ao consumismo desenfreado, algo que leva ao descuido com a própria saúde.

\section{Livros Didáticos e a Educação Ambiental na articulação com a Saúde}

Em atenção ao que traz de EA nos LD de Química, também nos propusemos a contextualizar possíveis articulações considerando a questão da saúde e alimentação, sustentando, “[...] o princípio de que a relação dialética entre alimentação e saúde é indissociável, do qual podemos reconhecer causas e consequências provenientes desta relação" (DAMO, 2012, p. 37). O posicionamento de considerar a saúde na perspectiva ambiental, decorre da intrínseca relação entre ambas. Entendendo que é necessário explorar esse tema, mencionando aspectos, que por vezes, passam despercebidos, a exemplo, da na alimentação que recai sobre a saúde. 
Diante do exposto, permear o estudo sobre saúde por meio da EA no LD, torna-o ainda mais comprometedor com uma educação integrada com as questões sociais, culturais, ambientais, haja vista, ser o LD ser uma ferramenta utilizada pelos professores nas escolas. Ainda, constitui uma forma de disseminar uma concepção acerca da EA, podendo ser determinista em uma ideologia para novas discussões de sustentabilidade.

No intuito de perpassar a EA e a relação com a saúde destacamos no decorrer desta discussão um excerto por LD abordando os excertos que fazem menção, ou que mais se aproximam da relação EA. Junto a isso, observamos em que momento no capítulo foi encontrado, como no decorrer do texto do conteúdo, textos adicionais, quadros e atividades e também as sugestões e/ou momentos que a EA poderia ser introduzida no debate pelo professor junto aos alunos.

Desse modo, o LD1 aponta junto ao conteúdo de separação de misturas (tratamento da água), algumas doenças causadas pela "poluição biológica” da água, e que "no Brasil estimase que de $80 \%$ a $90 \%$ das internações hospitalares ocorrem por causa de doenças transmitidas pela água" (FONSECA, 2016, p. 60). Tal excerto é complementado por outro, encontrado em um quadro: "Estou falando aqui sobre as condições nos países desenvolvidos, em que a indústria está estabelecida há muito tempo e a saúde pública tem sido uma preocupação há mais de um século (FONSECA, 2016, p. 239).

Neste LD1 é citado várias vezes o tema mudanças climáticas, o professor poderia instigar os alunos a descobrir quais os danos à saúde que estas mudanças podem provocar e como a reciclagem e o tratamento da água influenciam sobre nossa saúde.

Assim também com o LD2, o qual contempla algumas temáticas que permitem ao professor articular a EA com a saúde e alimentação. Esse diálogo em sala de aula se faz necessário, pois compreendemos que ao passo que a população mundial aumenta, a pressão sobre os recursos naturais, especialmente para a produção de alimentos, dispara substantivamente. Desse modo, é necessário um trabalho efetivo em ações de EA na conscientização ambiental da população. Incentivar práticas que evitem o desperdício e o consumo exagerado é de fundamental importância.

Neste sentido, o LD2 na sessão retomando a notícia, aponta para os problemas de saúde que podem ser desenvolvidos quando a umidade relativa do ar está muito baixa ou muita alta. O texto traz as complicações em relação a umidade e os cuidados a serem tomados. "A baixa umidade relativa do ar pode trazer [...] ressecamento da pele e irritação dos olhos, [...]. Também aumenta a probabilidade de ocorrência de incêndios em pastagens e florestas" (FONSECA, 2016, p. 42), cabendo ao professor articular diretamente com o 
conteúdo de Química a questão da EA, cabendo contextualizar com as perspectivas socioambientais, entendo a problemática em contexto local/global.

Em tal LD, o aspecto da poluição da água e o esgoto estão relacionadas diretamente a saúde e EA, pois: “O esgoto que corre a céu aberto é considerado um dos maiores problemas ambientais e de saúde pública do país” (FONSECA, 2016, p. 74). Assim, a questão abordada ajuda a orientar o professor em sua prática pedagógica, propondo que ele desafie os alunos a investigar como está a situação do tratamento da água e esgoto na cidade. A EA: “[...] bem ensinada e bem aprendida tem de ter relação com a vida das pessoas, o seu dia a dia, o que elas veem e sentem, o seu bairro, a sua saúde, as alternativas ecológicas" (MINC, 2005, p. 72).

Ainda, quanto ao lixo eletrônico, “[...] o problema é que com os metais preciosos também são encontrados vários metais tóxicos que, ao serem expostos ao meio ambiente, contaminam o ar, a água, o solo, os alimentos e a saúde daqueles que os manipulam” (FONSECA, 2016, p. 285), visto a importância da articulação com a saúde e alimentação. Em tal caso, cabe a discussão para os aspectos políticos e econômicos envolvidos na questão, uma vez que "[...] nada se resolve sobre a temática ambiental, sem decisão política” (DIAS, 2000, p. 121).

E sobre os excertos encontrados no LD3, apenas dois (2) estão inseridos ao conteúdo, no entanto, estão em outras sessões como retomando a notícia. Um deles trata dos aditivos químicos nos alimentos, destacando que: “[...] nem sempre são saudáveis quando consumidos em grande quantidade, já que estão distribuídos em diversos alimentos consumidos ao longo do dia" (FONSECA, 2016, p. 226). O outro excerto traz sobre um acidente ambiental com césio-137 ocorrido em Goiânia no ano de 1987, este acidente acarretou na morte de cerca de 64 pessoas e contaminou 249 pessoas (FONSECA, 2016).

Apontamos para um assunto interessante que surgiu em uma das sessões, a Química Verde, esta que poderia ser trabalhada no contexto da alimentação e da saúde, pois entendemos que, "[...] estuda o desenvolvimento de produtos e processos químicos que reduzam ou eliminem o uso e a geração de substâncias perigosas [...] aos seres humanos e ao meio ambiente" (FONSECA, 2016, p. 154).

Destarte, por meio deste estudo, evidenciamos a existência de lacunas quanto à abordagem da EA na ótica da alimentação e saúde que precisaria ser trabalhada com mais afinco, pois neste estudo trazemos praticamente a essência do que foi exposto no LD o que requer a ampliação com atenção à EA. Registramos a importância da inclusão dessa temática como item de seleção dos LD pelo PNLD. Enfim, com este estudo visamos contribuir para 
que o professor na escolha do LD se posicione de forma crítica também pela questão da EA, sendo consciente e condizente com a realidade de seus educandos para nortear as discussões que propiciem mudanças atitudinais no cuidado do meio ambiente.

\section{Conclusão}

Foi destaque neste estudo a temática da EA, em atenção ao que refere a relação com a saúde e alimentação, observando os excertos sobre os mesmos nos LD de Química. A relação entre e na temática da EA nem sempre ocorre, ficando muitas vezes separadas do conteúdo de modo que passa despercebido com a função social da escola, visto a relação com a realidade do aluno na assimilação e construção dos conceitos escolares pelos alunos.

O LD está, de certa forma, organizado de um modo linear, pois pouco se contextualiza com o tema transversal como da EA, principalmente na relação com o conteúdo de Química, por exemplo. Cabe ampliarmos as discussões para elevar a interação dos conceitos de Química focados no cuidado com o meio ambiente e alimentação, pois tudo que afeta a natureza, reflete em nossa saúde, pois estamos sempre em contato com o ar, alimento, água, enfim com os produtos que advém da natureza.

Portanto, destacamos a importância de introduzir na educação a questão da interação com a EA relacionada ao contexto em atenção à realidade dos alunos. O que requer maior atenção aos materiais didáticos usados nas escolas, como do LD, a respeito da EA, possibilitando aos alunos uma formação cidadã, crítica e, principalmente de conhecimento de temáticas emergentes como da EA, tanto para o professor quanto para os alunos e sociedade em geral no conhecimento e preservação do ambiente, consequentemente da própria saúde.

\section{Referências}

BRASIL. Secretaria de Educação Fundamental. Parâmetros curriculares nacionais: meio ambiente, saúde / Secretaria de Educação Fundamental. - Brasília: 128p. Parâmetros curriculares nacionais. Volume: 2. Meio Ambiente. Volume: 3. Saúde: Ensino de primeira à quarta série, Brasília, 1997.

DIAS, G. F. Educação Ambiental: Princípios e Práticas. 6. ed. São Paulo: Gaia, 2000.

DAMO, A. Educação Ambiental, Qualidade Alimentar e Saúde: Estudo de Caso das Representações Sociais dos Consumidores da Feira Ecológica da FURG. Dissertação (Mestrado), Universidade Federal do Rio Grande, Mestrado em Educação Ambiental, Rio Grande, 2012.

FONSECA, M. R. M. da. Química. São Paulo: Ática, 2016. 
GERALDI, C. M. G. Currículo em ação: buscando a compreensão do cotidiano na escola básica. Pro-Posições. v.5, n.3. UNICAMP, 1994. Disponível em:

$<$ https://periodicos.sbu.unicamp.br/ojs/index.php/proposic/article/view/8644307/11731>. Acesso em: 10 de setembro de 2018.

GÜLLICH, R. I. da C.; KIEREPKA, J. S. N.; HERMEL, E. E. S. Problematizando categorias de enredo do livro didático de ciências. IX ANPED SUL - Seminário de Pesquisa em Educação da Região Sul, 2012. Disponível em:

<http://www.ucs.br/etc/conferencias/index.php/anpedsul/9anpedsul/paper/viewFile/1767/292 $>$. Acesso em: 10 de setembro de 2018.

LOUREIRO, C. F. B. Trajetória e Fundamentos da Educação Ambiental. 2. ed. São Paulo: Cortez, 2006.

MINC, C. Ecologia e Cidadania. 2. ed. São Paulo: Moderna, 2005.

NEVES, S. G. Educação Ambiental nos Livros Didáticos: região da Grande Dourados-MS (1979-2002). Horizontes - Revista de Educação, 2014.

SANTOS, M. G. de F. N. dos. Educação Ambiental no Livro Didático Brasileiro. Inter-ação: Revista da Faculdade de Educação da UFG. v.33, n. 1, p.49-70, jan./jun. 2008. Disponível em: <https://www.revistas.ufg.br/interacao/article/view/4242/4172>. Acesso em: 10 de agosto de 2018.

SOFFIATI, A. Fundamentos filosóficos e históricos para o exercício da ecocidadania e da ecoeducação. In: LOUREIRO, Carlos Frederico Bernardo; LAYRARGUES, Philippe Pomier; CASTRO, Ronaldo Souza de (org). Educação Ambiental: repensando o espaço da cidadania. São Paulo: Cortez, 2002. p. 23-67.

TRISTÃO, M. A Educação Ambiental na Formação de Professores: redes de saberes. São Paulo: Annablume, 2004.

UHMANN, R. I. M. Interações e Estratégias de Ensino de Ciências com foco na Educação Ambiental. Curitiba: Appris, 2013.

UHMANN, R. I. M.; ZANON, L. B. Ações Pedagógicas no Ensino de Física com Foco na Educação Ambiental. Revista Eletrônica de Mestrado em Educação Ambiental - REMEA do Mestrado da Universidade Federal do Rio Grande - FURG, Rio Grande-RS, 2012. Disponível em: <https://periodicos.furg.br/remea/article/view/2944>. Acesso em: 01 de setembro de 2018. 